\title{
Yarı Kurak Bölge Koşullarında Zeytin Bitkisinin Yetiştiği Toprakta Karbondioksit Emisyonunun Ölçülmesi
}

Measurement of $\mathrm{CO}_{2}$ Emissions in the Semi - Arid Region Conditions in the Soil where the Olive Plant Grows

\author{
Erdal SAKİN ${ }^{1}$, Korkmaz BELLITTÜRK ${ }^{2 *}$, Ahmet ÇELİK ${ }^{3}$
}

\section{$\ddot{O} z$}

Tarımsal faaliyetler ve bileşenleri büyük oranda iklimsel olaylara dayanır. Özellikle sıcaklık ve $\mathrm{CO}_{2}$ düzeylerindeki yükselme tarımsal üretimin geleceğini belirleyen en önemli parametredir. Dünya atmosferinde $\mathrm{CO}_{2}$ miktarının giderek artması, sera etkisi yapan diğer gazlarla birlikte global iklim değişikliğine ve sıcaklı̆ğı artmasına neden olmaktadır. Yine bu değişimlerin yanında düzensiz mevsimler, kuraklık, toprak verimliliğinin azalması ve erozyon, su kaynaklarında azalma, doğal bitki örtüsündeki değiş̧im, gıda yetersizliği/güvenliği, hastalıkların ve zararlıların yaygınlaşması iklim değişikliğinin olumsuz etkileri arasında yer almaktadır. $\mathrm{Bu}$ olumsuzluklar Dünya ve Türkiye açısından önemli düzeyde risk oluşturmaktadır. Türkiye'de yetiştiriciliği oldukça eski dönemlere dayanan zeytin bitkisinin Güneydoğu Anadolu Bölgesi’nde son dönemlerde tarımı, kullanımı ve ticareti hızla ivme kazanmıştır. Bu nedenle yapılan bu araştırmada zeytin bitkisinin yetiştiği ortamlarda topraktan çıkan $\mathrm{CO}_{2}$ emisyonuna etki eden faktörlerin (sıcaklık ve nem) incelenmesi ve ölçülmesi amaçlanmıştır. Araştırma Harran Üniversitesi Eyyubiye kampüsünde zeytin bitkisinin yetiştiği alanda 56 hafta süresince 3 tekrarlı olarak 5 örnekleme alanında yürütülmüştür. Çalışma alanı topraklarının bazı fiziksel ve kimyasal özellikleri de bu çalışma kapsamında belirlenmiştir. İklimsel veriler, inceleme alanında kurulan Decagon data logger (5 TE, EM50 Data Logger) ile 30 dakika bir süre ile ölçülmüştür. Topraktan $\mathrm{CO}_{2}$ çıkışı Soda-Lime yöntemi ile ölçülmüştür. Analizlerde R (CorLevelPlot package) Minitab 17 istatistik paket programı kullanılmıştır. Araştırma sonuçlarına göre, topraktan salınan $\mathrm{CO}_{2}$ emisyonu üzerine toprak sıcaklığının etkisi toprak neminin etkisinden daha fazla olduğu saptanmıştır. Topraktan $\mathrm{CO}_{2}$ çıkışı toprak sıcaklığı ile doğru $\left(\mathrm{r}^{2}=0.695, \mathrm{p}<0.05\right)$, toprak nemi ile ters $\left(\mathrm{r}^{2}=\right.$ $0.626, \mathrm{p}<0.05)$ bir korelasyon saptanmıştır. Toprak sıcaklığ $16^{\circ} \mathrm{C}$ 'nin altına düştüğünde topraktan çıkan $\mathrm{CO}_{2}$ miktarının minimum düzeyde olduğu ve bu noktanın da kritik toprak sıcaklık noktası olduğu belirlenmiştir. Araştırma topraklarında $\mathrm{CO}_{2}$ çıkışı, farklı derinlik, nem ve sıcaklık miktarlarına bağlı değişmekle beraber ortalama $55.56 \mathrm{~g} \mathrm{CO}_{2} \mathrm{~m}^{-2}$ hafta $^{-1}$ olarak saptanmıştır.

Anahtar Kelimeler: $\mathrm{CO}_{2}$ Emisyonu, Zeytin, İklim Değişikliği, Sıcaklık, Nem

\footnotetext{
${ }^{1}$ Erdal Sakin, Harran Üniversitesi Ziraat Fakültesi Toprak Bilimi ve Bitki Besleme Bölümü, Şanlıurfa/Türkiye. E-mail: esakin@harran.edu.tr (D) OrcID: 0000$0001-5403-4247$.

${ }^{2 * S o r u m l u ~ Y a z a r / C o r r e s p o n d i n g ~ A u t h o r: ~ K o r k m a z ~ B e l l i t u ̈ r k, ~ T e k i r d a g ̆ ~ N a m ı k ~ K e m a l ~ U ̈ n i v e r s i t e s i ~ Z i r a a t ~ F a k u ̈ l t e s i ~ T o p r a k ~ B i l i m i ~ v e ~ B i t k i ~ B e s l e m e ~ B o ̈ l u ̈ m u ̈, ~}$ Tekirdağ/Türkiye. E-mail: kbelliturk@hotmail.com DOrcID: 0000-0003-4944-3497.

${ }^{3}$ Ahmet Çelik, Adıyaman Üniversitesi Tarım Bilimleri ve Teknolojileri Fakültesi, Ziraat Mühendisliği Bölümü, Adıyaman/ Türkiye. E-mail: ahmetcelik@adiyaman.edu.tr (D) OrcID: 0000-0001-8958-4978.

Atıf/Citation: Sakin, E., Bellitürk, K., Çelik, A. Yarı Kurak Bölge Koşullarında Zeytin Bitkisinin Yetiștiği Toprakta Karbondioksit Emisyonunun Ölçülmesi. Tekirdağ Ziraat Fakültesi Dergisi, 18 (3), 482-493.

CBu çalışma Tekirdağ Namık Kemal Üniversitesi tarafından Creative Commons Lisansı (https://creativecommons.org/licenses/by-nc/4.0/) kapsamında yayınlanmıştır. Tekirdağ 2021
} 


\begin{abstract}
Agricultural activities and their components are largely based on climatic events. Especially the rise in temperature and $\mathrm{CO}_{2}$ levels is the most important parameter that determines the future of agricultural production. Increasing amount of $\mathrm{CO}_{2}$ in the world atmosphere causes global climate change and temperature increase together with other gases that cause greenhouse effect. In addition to these changes, irregular seasons, drought, decrease in soil fertility and erosion, decrease in water resources, change in natural vegetation, food insufficiency / security, spread of diseases and pests are among the negative effects of climate change. These problems pose a risk in terms of significant world and Turkey. Agriculture use and trade of the olive plant, the cultivation of which dates back to very old eras in Turkey, has gained momentum in the Southeastern Anatolia Region recently. For this reason, in this study, it is aimed to examine and measure the factors (temperature and humidity) affecting the $\mathrm{CO}_{2}$ emission from the soil in the environments where the olive plant grows. The research has been carried out in Harran University Eyyubiye campus in 5 sampling areas with 3 repetitions for 56 weeks in the area where the olive plant grows. Some physical and chemical properties of the study area soils were determined. The climatic data were determined for a period of 30 minutes with the Decagon data logger (5 TE, EM50 Data Logger) installed in the study area. $\mathrm{CO}_{2}$ output from soil has been measured by the Soda-Lime method. In the analysis, $\mathrm{R}$ (CorLevelPlot package) Minitab 17 statistics package program has been used. According to the results of the research, it has been determined that the effect of the soil temperature on the $\mathrm{CO}_{2}$ emission released from the soil is higher than the effect of the soil moisture. It has been determined that $\mathrm{CO}_{2}$ output from soil correlated directly with soil temperature $(\mathrm{r} 2=0.695, \mathrm{p}<0.05)$ and correlated inversely with soil moisture $(\mathrm{r} 2=-0.626, \mathrm{p}<0.05)$. It has been determined that when the soil temperature drops below $6{ }^{\circ} \mathrm{C}$, the amount of $\mathrm{CO}_{2}$ released from the soil is at a minimum level, and this point is the critical soil temperature point. Although the $\mathrm{CO} 2$ output in the research soils varies depending on the different depth, moisture and temperature amounts, the average was determined as 55.56 $\mathrm{g} \mathrm{CO}_{2} \mathrm{~m}^{-2}$ weeks ${ }^{-1}$.
\end{abstract}

Keywords: $\mathrm{CO}_{2}$ Emission, Olive, Climate Change, Temperature, Humidity 


\section{Giriş}

İnsanların geleceğini tehdit eden birincil çevresel sorunların başında küresel iklim değişimi gelmektedir. Dünya'da yıllık sıcaklık ortalamalarını hızla artması, düzensiz mevsimler, gıda yetersizliği/güvenliği, hastalıkların ve zararlıların yaygınlaşması iklimsel değişikliklerin olumsuz etki ve risklerini ortaya koymaktadır. İklim değişimine sebep olan başlıca etkenin sera gazlarının $\left(\mathrm{CO}_{2}, \mathrm{~N}_{2} \mathrm{O}, \mathrm{CH}_{4} \mathrm{vb}\right)$ atmosferdeki yoğunluklarının artması olduğu gösterilmektedir (Nowak ve Crane, 2002; Schimel ve ark., 2000). Topraktaki çeşitli mikroorganizma faaliyetleri ve bitki köklerinden çıkan karbondioksit'in $\left(\mathrm{CO}_{2}\right)$ zamansal ve mekânsal faktörler altında atmosfere salınması 'toprak solunumu' olarak tanımlanmaktadır (Raich ve Schlesinger, 1992). Toprak solunumundaki bir artış, atmosferdeki $\mathrm{CO}_{2}$ değerlerini potansiyel olarak yükseltecektir. Böylece atmosferdeki $\mathrm{CO}_{2}$ artışları ve bununla ilgili olarak iklimdeki potansiyel değişimde, biyosferik karbon akışlarının belirlenmesi oldukça büyük önem taşımaktadır (Raich ve Schlesinger, 1992). Ayrıca atmosferik $\mathrm{CO}_{2}$ 'in artması ile artan global ssınmayı ve doğabilecek olumsuzlukları önlemek amacıyla son 30 yıllık süreçten günümüze kadar çalışmalar yapılmaktadır. Ancak çalışmalar istenilen düzeye erişmemiştir. Toprak solunum oranının ölçülmesi hem atmosfere ne oranda $\mathrm{CO}_{2}$ salındığının belirlenmesinde hem de uygulaması kolay ve ucuz olduğundan, toprak kirliliği çalışmalarında da çok kullanılan bir yöntemdir. Bu yöntemle topraktaki toplam mikrobiyal aktivitelerin belirlenmesi de sağlanır. Ayrıca orman ekosistemlerinde asit depolanmasının etkilerinin belirlenmesinde olduğu kadar ağır metallerin etkilerinin ortaya konulmasında da kullanılmaktadır (Vanhala ve ark., 1996). Toprak solunumu hem zamansal hem de mekânsal olarak çok büyük değişkenlik gösterir. Zaman faktörü günlük, aylık ve yıllık süreçlerden oluşmaktadır. $\mathrm{Bu}$ süreçlerde toprak solunumunu etkileyen önemli faktörler toprak sıcaklığı ve toprak nemidir (Goncharova ve ark., 2020). Mekânsal faktörler ise toprağın fiziksel, kimyasal ve biyolojik (vejetasyon tipi ve yoğunluğu, kök yoğunluğu, mikroorganizma faaliyetleri vb.) özelliklerini kapsamaktadır (Dignac ve ark., 2017).

Atmosfere salınan karbondioksitin büyük miktarı tarımsal faaliyetler sonucu meydana gelmiştir. Tarımsal uygulamalardan, özellikle pullukla toprak işleme, anız yakma ve ekim nöbeti uygulanması $\mathrm{CO}_{2}$ çıkışı artı̧̧ında çok önemli role sahiptir (Lal ve Kimbele, 1997). Son yıllarda yapılan bilimsel araştırmalarda, toprak karbon stoklarındaki hızlı oksidasyonun çevrede özellikle atmosferin kimyasında önemli değişmelere neden olduğunu ortaya koymuştur. Atmosferdeki sera gazlarından özellikle $\mathrm{CO}_{2}$ 'nin miktarındaki artış eğilimi iklim, bitkilerin fizyolojisi, toprağın mikrobiyal aktivitesi ve organik maddenin oluşumu ve parçalanmasına önemli ölçüde etki eden faktörlerin başında gelir (Bellitürk, 2019). Topraklar atmosferdeki $\mathrm{CO}_{2}$ için bir depo yeri olabileceği gibi emisyon kaynağı da olabilir. Bir ekosistemde toprakta depolanan veya topraktan atmosfere salınan C miktarı, net ekosistem üretimi ile ekosistemden atmosfere salınan toplam heterotrofik solunuma bağlıdır. Arazinin kullanımına bağlı olarak yoğun toprak işleme, topraktaki organik C'un hızla oksidasyonun toprakların atmosferdeki $\mathrm{CO}_{2}$ için bir kaynak olmasına neden olmaktadır. Topraklar yıllardır uygulanan geleneksel toprak işleme sonucu sahip olduğu başlangıç karbon düzeyinin yaklaşı \% 50 'sini kaybetmiş durumdadır.

Toprak işlemede yoğun enerji kullanımı, insan sağlı̆ı̆ı etkileyen ve sera gazı (GHG) emisyonları gibi önemli çevre sorunlarını ortaya çıkarmaktadır (Karaağaç ve ark., 2019). Bu sorunları azaltmak için, minimum sürüm ve işlemesiz tarım teknikleri organik karbonun oksidasyonunu düşürerek toprağın net $\mathrm{C}$ kazanmasına neden olur. Böylece çeşitli yollarla atmosfere salınmış olan C'nin yeniden toprakta depolanması sağlanabilir. Yüksek organik karbon aynı zamanda toprağın verimliliğini ve kalitesini de artırır. Böylece topraklar atmosferdeki karbonun depolanması için iyi bir kaynak görevi görür. Topraklar, karbondioksitin önemli küresel kaynağı ve deposudur. Bundan dolayı karbondioksitin atmosferdeki yoğunluğunun düzenlenmesinde önemli rol oynar. Yapılan araştırmalarda her yıl atmosferdeki karbondioksit yoğunluğunun yaklaşı \%10'u toprak yoluyla atmosfere geçmektedir. Bu miktar fosil yakıtların yanmasıyla ve ormansızlaşma ile açığa çıkan $\mathrm{CO}_{2}$ miktarından yaklaşık 10 kat daha yüksek düzeydedir (Raich ve Schlesinger, 1992).

Topraklar, karbon depolanması ve emisyonlarını dengelemek için çok önemli bir ortam oluşturur. Toprak organik maddesi ve inorganik karbonatlar pedosferde iki büyük karbon havuzu olup ve birbiriyle yakından ilgilidir. Kurak bölgelerde sulama ile toprağa $\mathrm{CO}_{2}$ 'in bağlanma şansının yüksek olması nedeniyle (Çelik ve Sakin, 2017), Türkiye'de yeni sulamaya açılacak ve mevcut sulanan alanlarda ayrıntılı çalışmalar yapıllmasına büyük gereksinim duyulmaktadır.

Gelecekte daha sıcak ve kurak koşulların söz konusu olduğu bir süreçte, daha kurakçıl ve sıcak koşullara uygun tarımsal bitki çeşitlerinin belirlenmesi gerekmektedir (Yaldız ve Şekeroğlu, 2013). Bunun dışında alınması 
gereken diğer bir önlem de kuraklığa karşı toprak su tutma kapasitesinin artırılmasına yönelik kültürel işlemlerden organik gübre kullanımının da yaygınlaştırılması son derece önemlidir (Çelik ve ark., 2017). Bu konuda organik gübrelerden vermikompost uygulamalarının toprakta su tutma kapasitesini artırdığı belirlenmiştir. Organik gübrelerin ve vermikompost uygulamasının mikrobiyal aktiviteyi olumlu yönde etkilemekte olup, heterotrofik mikroorganizmalar tarafindan enerji sonucunda son ürün olarak ortaya çıkan $\mathrm{CO}_{2}$ seviyesi, organik karbonun mineralizasyonu hakkında önemli bilgiler verir (Açıkbaş ve Bellitürk, 2016; Bellitürk, 2018; Görres ve ark., 2019; Bellitürk ve ark., 2019;Bellitürk, 2019; Göçmez ve ark., 2019).

Türkiye'nin uygun ekolojilerinde kültür şartlarında ve özellikle yarı kurak bölge topraklarında yetiştirilen zeytin bitkisinin dikim alanı açısından yaygınlaştırılması ve kullanımı her geçen gün önem kazanmıştır (Çimrin ve ark., 2019). Hazırlanan bu çalışmada, Harran Üniversitesi Eyyubiye kampüsünde bulunan zeytin ağaçlarının yetiştiği toprakların solunumu ve solunuma etki eden faktörlerin incelenmesi amaçlanmıştır. Ayrıca yine bu çalışmayla elde edilen bulguların küresel ve yerel karbon döngüsünün önemli bir parçası olan toprak solunumu ile ilgili altlık verilerin sağlanması hedeflenmiş̧ir.

\section{Materyal ve Metot}

\section{1. Örnekleme Yöntemi}

Çalışma alanı Harran Ovası'nda $37^{\circ} 09^{\prime} 02^{\prime \prime} \mathrm{N}$ enlemleri ile $38^{\circ} 48^{\prime} 57^{\prime \prime}$ E boylamları arasında yer alan Eyyubiye kampüsünde zeytinlik alanda yürütülmüştür (SSekil l). Deneme alanının denizden yüksekliği 466 m'dir. Harran Üniversitesi Eyyübiye kampüsünde zeytin bitkisinin yetiştiği alanda 56 hafta süresince 3 tekrarlı olarak 5 örnekleme alanında yürütülmüştür.

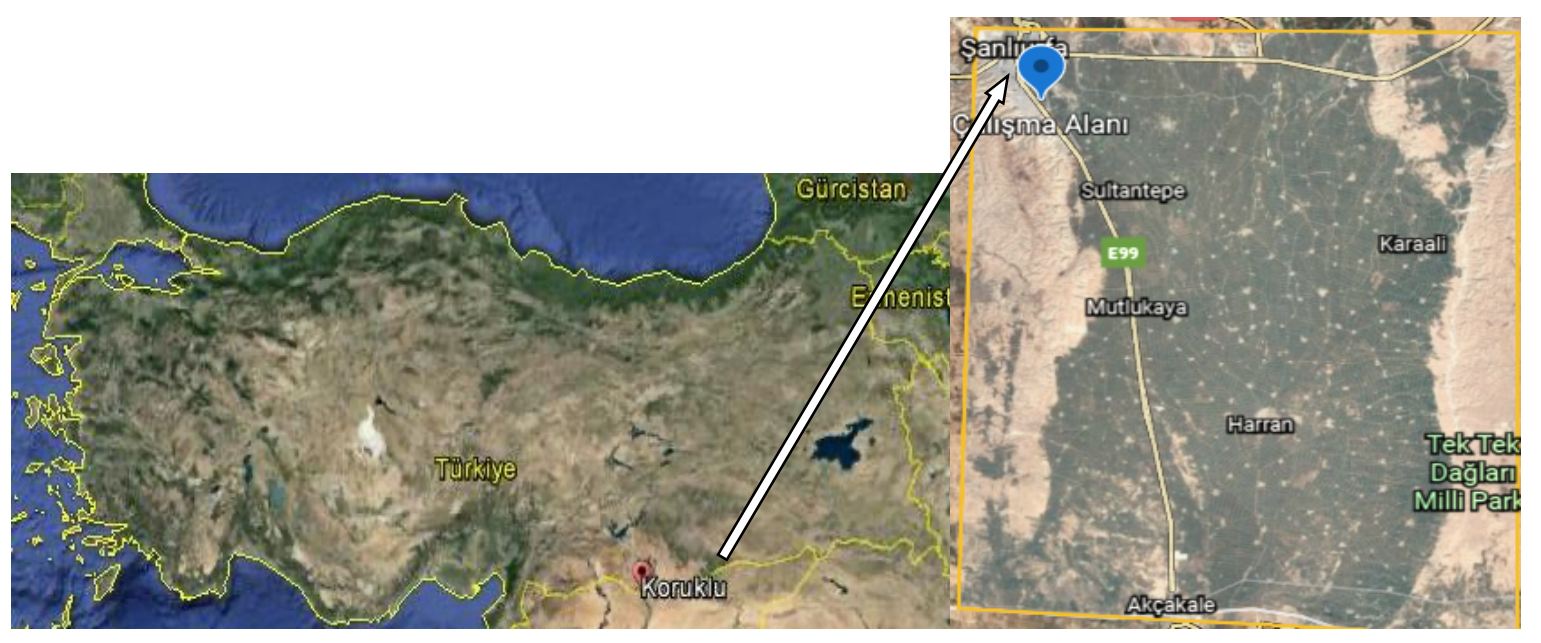

Figure1. Location of the study area

Şekil 1. Çalışma Alanının Konumu

\subsection{Laboratuvar Analizleri}

Toprakların bazı fiziksel ve kimyasal özelliklerini belirlemek için 0-5 ve 5-10 cm derinliğinde toprak örnekleri alınmış, kurutulmuş ve $2 \mathrm{~mm}$ 'lik elekten geçirilmiştir. Toprakların parçacık büyüklük dağılımı (tekstür) (Bouyoucos, 1951), kireç içeriği (Scheibler kalsimetresi) (Allison ve Moodie, 1965), organik karbon içeriği (Walkley-Black) (Nelson ve Sommers, 1982), toprak reaksiyonu (pH) 1:2.5 toprak/su süspansiyonunda ve elektriksel iletkenlik (EC) (Horneck ve ark., 1989) ve hacim ağırlığı (Black, 1965) analizleri yapılııışır. Çalışma alanı toprakları killi, kireçli, organik karbon miktarı düşük, hafif alkali olup, tuzluluk problemi bulunmamaktadır (Tablo 1). 
Table 1. Some physical and chemical properties of work area soils

\begin{tabular}{lcc}
\hline \multicolumn{1}{c}{ Toprak Parametreleri } & Derinlik (0-5 cm) & Derinlik (5-10 cm) \\
\hline Toprak Reaksiyonu; pH (1:2.5) & 7.55 & 7.69 \\
Elektriksel İletkenlik; EC (1:2.5) & 0.91 & 0.94 \\
Organik Karbon; OC (\%) & 2.01 & 1.96 \\
Hacim Ă̆ı̆lığı; HA $\left(\mathrm{g} / \mathrm{cm}^{-3}\right)$ & 1.26 & 1.28 \\
Kireç İçeriği (\%) & 25.11 & 29.09 \\
Kil (\%) & 52.56 & 50.56 \\
Kum (\%) & 26.42 & 24.46 \\
Silt (\%) & 21.02 & 24.98 \\
Tekstür sınıfi & $\mathrm{C}$ & $\mathrm{C}$ \\
\hline
\end{tabular}

\section{3. İklim Verileri}

Çalışmanın yürütüldüğü bölgenin iklimi kurak ve yarı kurak olup, kışlar ılık, yazlar kurak ve sıcaktır. İklim verilerine göre, yıllık ortalama sıcaklık $18.4^{\circ} \mathrm{C}$, yıllık ortalama yağış düzeyi $463.6 \mathrm{~mm}$, en yüksek sıcaklık $46.8^{\circ} \mathrm{C}$ ile Temmuz, en düşük sıcaklık ise $-12.4^{\circ} \mathrm{C}$ ile Şubat ayında saptanmıştır (Anonim, 2019). İklim verileri deneme alanında kurulan Decagon data logger (5TE, EM50 Data Logger) yardımıyla 30 dakikada bir ölçülmüştür. Elde edilen veriler günlük, haftalık, aylık ve yıllık olmak üzere alınmış ve aynı tarihlerde alınan $\mathrm{CO}_{2}$ çıkış miktarları ile karşılaştırılmıştır. İklim verileri hava sıcaklığı, bağıl nem, PVC kabın iç sıcaklı̆ı̆ iç nemi, PVC kabın kapladığı toprak alanının $5 \mathrm{~cm}$ derinliğindeki toprak sıcaklığı, toprak nemi ve toprağın elektriksel kondaktivitesi, açık alandaki (PVC kabın olmadığı) toprağın 5 ve $10 \mathrm{~cm}$ derinlikteki toprak sıcaklı̆̆ı, toprak nemi ve toprağın elektriksel kondaktivitesi ölçülmüştür. Alınan bu veriler topraktan çıkan $\mathrm{CO}_{2}$ değerleri ile ilişkilendirilmiştir.

\subsection{Karbondioksit ( $\left.\mathrm{CO}_{2}\right)$ Emisyonunun Ölçülmesi}

$\mathrm{Bu}$ çalışmada, Harran Üniversitesi Eyyubiye kampüsünde zeytin yetiştirilen işlenmemiş toprakta $\mathrm{CO}_{2}$ emisyonunu belirlemek için, dünyada yapılan çalışmalarda pek çok araştırmacı tarafından tercih edilen, kolay ve ucuz olması (Keith ve Wong, 2006) nedeni ile Soda Lime (Soda Kireci) (Grogan, 1998) kullanılmıştır. Bu yöntemle $\mathrm{CO}_{2}$ kimyasal olarak soda-lime bağlamaktadır (Edwards, 1982). Soda Lime granüller yapıda olup granül büyüklüğü yaklaşık olarak 2-5 mm arasında değişen $\mathrm{CaOH}+\mathrm{NaOH}$ (kalsiyum ve sodyum hidrooksitler) karışımından ibarettir. Alkali (bazik) özelliğine sahip olan soda-lime $\mathrm{CO}_{2}$ 'i fikse etmektedir (Jae ve ark., 2011).

Ekolojik koşullara bağlı olarak alınan soda-lime miktarı değişmekle beraber genel olarak 50-100 g arasında değişmektedir. Bu çalışma için $50 \mathrm{~g}$ soda-lime alınmıştır. Çalışma işlenmemiş alanlarda 3 tekerrürlü olacak şekilde kurulmuş ve hesaplama aşağıdaki formüle göre yapılmıştır.

$$
\mathrm{ECO}_{2}=(\text { SLad-SLbas })^{*} W C /\left(A^{*} t\right)
$$

Burada $\mathrm{ECO}_{2}$, inkübasyon süresince çıkan toplam $\mathrm{CO}_{2}$ miktar $\left(\mathrm{g} \mathrm{CO}_{2} \mathrm{~m}^{-2}\right.$ gün $\left.{ }^{-1}\right) ; \mathrm{SLad}, \mathrm{CO}_{2}$ adsorbe etmiş soda lime miktarı (g); SLbaş, başlangıçtaki soda lime miktarı (g); A, alan $\left(\mathrm{m}^{2}\right)$; t, inkübasyon zamanı (arazide kalma süresi) (gün); WC, su düzeltme katsayısı 1.69 alınmıştır.

\section{5. İstatistik Analizler}

Analizlerde R (CorLevelPlot package) Minitab 17 istatistik paket programı kullanılmıştır.

\section{Araştırma Sonuçları ve Tartışma}

Toprakların haftalık karbon emisyon miktarları $\left(\mathrm{g} \mathrm{CO}_{2} \mathrm{~m}^{-2}\right)$ Şekil 2'de, günlük karbon emisyonu $\left(\mathrm{g} \mathrm{C} \mathrm{m}^{-2}\right)$ ve bazı iklim parametrelerinin tanımlayıcı istatistik değerleri Tablo 2'de ve günlük karbon emisyonu $\left(\mathrm{g} \mathrm{C} \mathrm{m}^{-2}\right)$ ile bazı iklim parametreleri arasındaki korelasyon Tablo 3'te verilmiştir. 
Haftalık ortalama $\mathrm{CO}_{2}$-C değeri $15.15 \mathrm{~g} \mathrm{C} \mathrm{m}^{-2}$ hafta $^{-1}\left(55.56 \mathrm{~g} \mathrm{CO}_{2} \mathrm{~m}^{-2}\right.$ hafta $\left.{ }^{-1}\right)$ olarak belirlenmiştir. $5 \mathrm{~cm}$ toprak derinliğinde haftalık ortalama toprak su içeriği \%11.66 (\%VWC) iken $10 \mathrm{~cm}$ toprak derinliğinde bu değer \%13.45 (\%VWC) olarak belirlenmiştir. Ortalama haftalık toprak sıcaklığ $5 \mathrm{~cm}$ toprak derinliğinde $22.53{ }^{\circ} \mathrm{C}$ iken $10 \mathrm{~cm}$ toprak derinliğinde $22.25{ }^{\circ} \mathrm{C}$ olarak ölçülmüştür. PVC kapları ile örtülen toprakların $5 \mathrm{~cm}$ toprak derinliğinde ortalama haftalık toprak su içeriği \%11.29, aynı alan ve aynı toprak derinliğinde toprak sıcaklığı $22.50{ }^{\circ} \mathrm{C}$ olarak saptanmıştır (Tablo 2). İklim parametrelerinin dışında toprak tekstürü, strüktürü, kimyasal ve biyolojik özelliklerde topraktan $\mathrm{CO}_{2}$ çıkışı üzerine etkilidir. Ayrıca, topraktaki organik karbon içeriği ve fonksiyonel karbon grupları ve diğer pek çok faktörlere bağlıdır.

Heterojen bir ortama sahip olan toprak katı, sıvı ve gaz fazlarından oluşmuştur. Bu ortam derinlik bakımından farklılık göstermektedir. Topraktan $\mathrm{CO}_{2}$ taşınımı alttan yüzeye doğru olmaktadır. Bu şekilde yüzeye doğru taşınan $\mathrm{CO}_{2}$ 'in bir kısmı atmosfere salınırken geri kalan kısım bazı kimyasal olaylara katılmaktadır. Toprak derinliğine bağlı olarak topraktaki $\mathrm{CO}_{2}$ yoğunluğu değişmektedir. Genel olarak derin olan toprakların $\mathrm{CO}_{2}$ yoğunluğu yüksek, yüzlek (derin olmayan) toprakların ise düşük olmaktadır.

Tablo 2. Topraktan $\mathrm{CO}_{2}-\mathrm{C}$ çılkısı ( $\mathrm{g} \mathrm{m}^{-1}$ hafta) ve bazı iklim parametrelerinin tanımlayıcı istatistik değerleri Table 2. $\mathrm{CO}_{2}$-C output from soil $\left(\mathrm{g} \mathrm{m}^{-1}\right.$ week) and descriptive statistics of some climate parameters

\begin{tabular}{lllllll}
\hline Değişken Parametreler & Ort. & $\begin{array}{l}\text { Standart } \\
\text { Hata Ort. }\end{array}$ & $\begin{array}{l}\text { Standart } \\
\text { Sapma }\end{array}$ & $\begin{array}{l}\text { Varyasyon } \\
\text { Katsayısı }\end{array}$ & Min. & Mak. \\
\hline Ort. $\mathrm{CO}_{2}$-C çıkışı $\left(\mathrm{g} \mathrm{m}^{-2}\right.$ hafta $\left.^{-1}\right)$ & 15.15 & 0.10 & 0.75 & 34.45 & 6.54 & 28.85 \\
Toprak su içeriği $(\% \mathrm{VWC}, 5 \mathrm{~cm})$ & 11.66 & 0.61 & 4.41 & 37.76 & 5.61 & 21.24 \\
Toprak sıcaklığı $\left({ }^{\circ} \mathrm{C}, 5 \mathrm{~cm}\right)$ & 22.53 & 1.57 & 11.35 & 50.39 & 5.65 & 39.39 \\
Toprak su içeriği $(\mathrm{VWC} \%, 10 \mathrm{~cm})$ & 13.45 & 0.61 & 4.37 & 32.47 & 7.97 & 22.42 \\
Toprak sicaklığı $\left({ }^{\circ} \mathrm{C}, 10 \mathrm{~cm}\right)$ & 22.25 & 1.46 & 10.50 & 47.20 & 6.74 & 37.44 \\
PVC kabın su içeriği $(\% \mathrm{VWC})$ & 11.29 & 0.98 & 7.08 & 62.67 & 2.21 & 29.43 \\
PVC kabın iç sıcaklığ $\left({ }^{\circ} \mathrm{C}\right)$ & 22.50 & 1.53 & 11.03 & 49.01 & 5.40 & 38.38 \\
\hline
\end{tabular}

Topraktan $\mathrm{CO}_{2}$ emisyonunun minimum ve maksimum değerleri sırasıly 22.64 ile $105.79 \mathrm{~g} \mathrm{CO}_{2} \mathrm{~m}^{-2}$ hafta $^{-1}$ arasında değişmektedir. İklim parametrelerine bağlı olarak mevsimsel değişen $\mathrm{CO}_{2}$ emisyon değerleri arasındaki farktan dolayı CV (varyasyon katsayısı)'ler ortalamanın üstüne çıkabilmektedir. Örneğin haftalık ortalama toprak sıcaklı̆̆ $(5 \mathrm{~cm})$ minimum $5.65{ }^{\circ} \mathrm{C}$, maksimum $39.39{ }^{\circ} \mathrm{C}$, aynı derinliğe ait toprak su içeriği ise sırasıyla $\% 5.612$ ile \%21.235 arasında değişmektedir. Haftalık ortalama toprak sıcaklığı ve toprak nemi gece ile gündüz arasındaki sıcaklık farkın yüksek olmasından kaynaklanmaktadır. Bu değerler haftalık ortalama sıcaklık ve nemin dalgalı çıkmasına ve CV'lerin yüksek olmasına neden olmaktadır (Tablo 2).

Deneme alanındaki toprakların $\mathrm{CO}_{2}$ emisyonu iklim parametrelerine bağlı olarak yıl içinde büyük değişimler göstermektedir. Karbondioksit emisyonu, 51'inci (Temmuz-Ağustos arası) haftada maksimum ve 28 'inci (Şubat ayı ortaları) haftada minimum düzeyde saptanmıştır. Bu haftalarda $\mathrm{CO}_{2}$ emisyonu 28 'inci haftada $22.64 \mathrm{~g} \mathrm{CO}_{2} \mathrm{~m}^{-}$ ${ }^{2}$ hafta $^{-1}$, 51 'inci haftada $105.79 \mathrm{~g} \mathrm{CO}_{2} \mathrm{~m}^{-2}$ hafta $^{-1}$ olarak ölçülmüştür (Şekil 2). Temmuz - Ağustos arasında bahçe sulaması nedeni ile $\mathrm{CO}_{2}$ çıkışı arttı̆̆ düşünülmektedir.

Burada $\mathrm{CO}_{2}$ çıkışının artması ve azalmasının temel nedeni toprak içerisinde yaşayan Mezofilik heterotrof mikroorganizmaların aktivitesinin toprak sıcaklığı ve nemine bağlı olarak artması ve düşmesidir. Bu nedenle toprak sıcaklığı ile topraktaki $\mathrm{CO}_{2}$ emisyonu arasında yüksek korelâsyonlar saptanmıştır ( $<<0.05$, Tablo 3). 


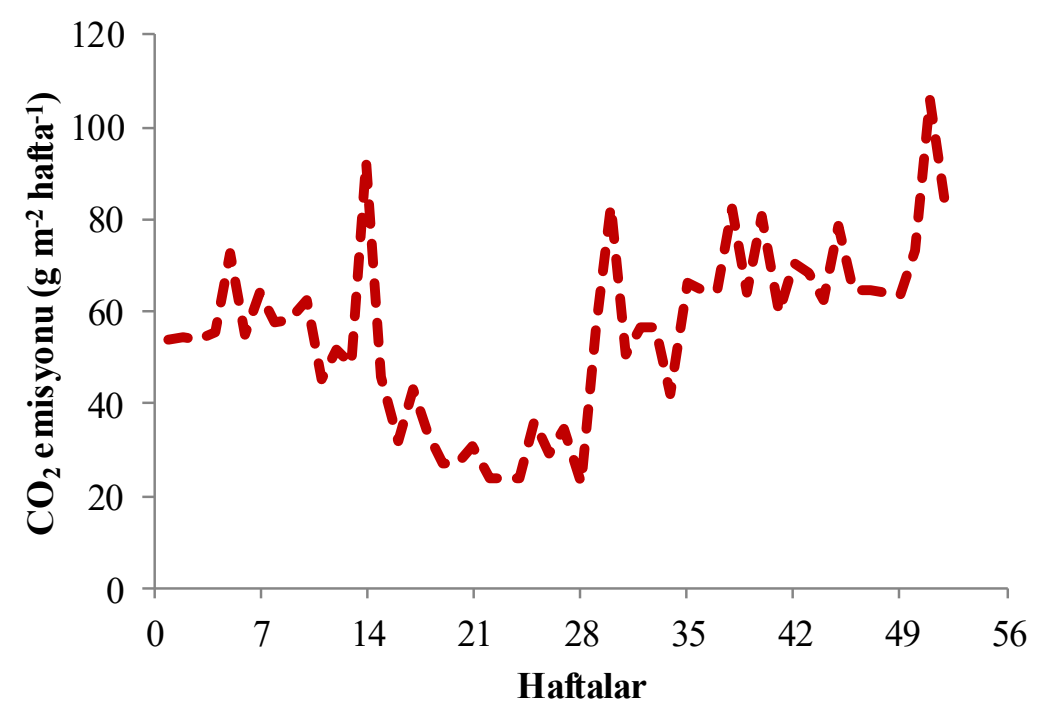

Figure 2. Weekly soil $\mathrm{CO}_{2}$ emission

\section{Şekil 2. Haftalık toprak $\mathrm{CO}_{2}$ emisyonu}

Bu haftalarda (14 ve 28'inci haftalar) $\mathrm{CO}_{2}$ emisyonuna karşllı gelen karbon emisyonu değerleri minimum $6.54 \mathrm{~g} \mathrm{C} \mathrm{m}^{-2}$ hafta $^{-1}$ ile maksimum $28.85 \mathrm{~g} \mathrm{C} \mathrm{m}^{-2}$ hafta $^{-1}$ arasında değişmektedir (Şekil 3). Yani maksimum ve minimum $\mathrm{CO}_{2}$ ve $\mathrm{C}$ emisyonu, iklim parametrelerinin minimum ve maksimum olduğu dönemlere denk gelmektedir.

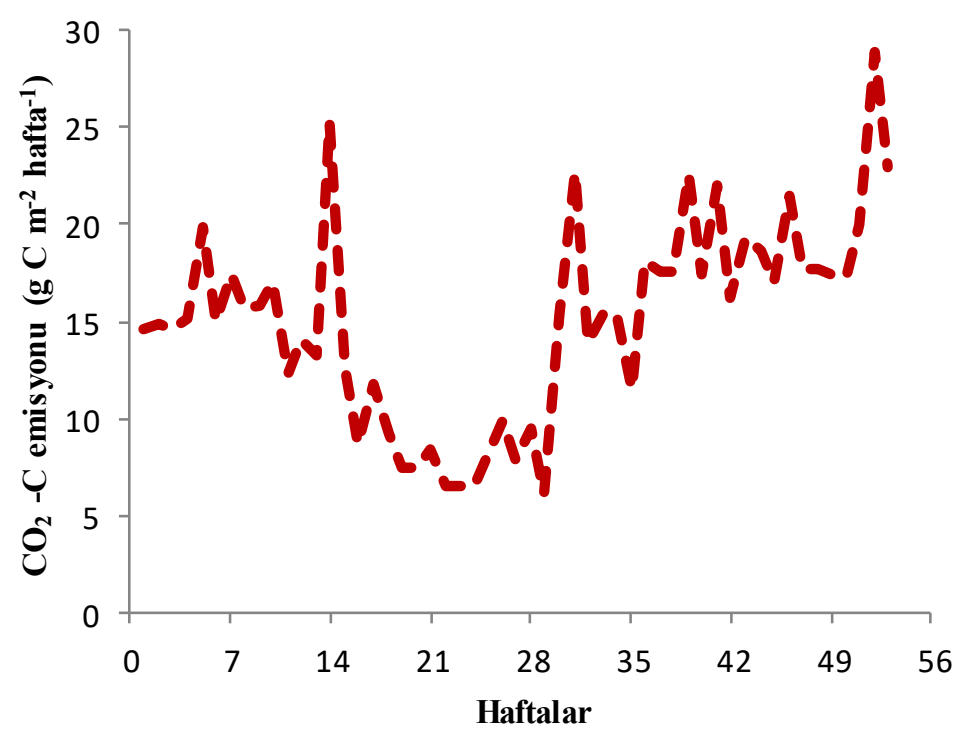

Figure 3. Weekly soil $\mathrm{CO}_{2}-\mathrm{C}$ emission

Şekil 3. Haftalık toprak $\mathrm{CO}_{2}-\mathrm{C}$ emisyonu

Toprak nemi ve sıcaklığı toprak canlılarının yaşam koşullarını etkilemektedir. Toprak sıcaklığı ile toprak nemi arasında ters bir ilişki bulunmaktadır. Toprak sıcaklığı azaldıkça nem artmakta, nem azaldıkça toprak sıcaklığı artmaktadır. Bu iki parametreye bağlı olarak topraktan çıkan $\mathrm{CO}_{2}$ miktarı değişmektedir. Topraktan $\mathrm{CO}_{2}$ çıkışı toprak sıcaklığına bağlı olarak bir dalgalanma (azalma-artma) göstermektedir. Toprak sıcaklığı $6{ }^{\circ} \mathrm{C}$ 'nin altına düştüğünde ve toprak su içeriği \%20'nin üstüne çıktığında topraktan çıkan $\mathrm{CO}_{2}$ miktarı minimum düzeydedir. Toprak sıcaklığ $120^{\circ} \mathrm{C}$ 'nin ve toprak su içeriği \%20'nin üstüne çıktı̆̆ında toprak sıcaklığı ve nemi arasında ters 
bir ilişki ortaya çıkmaktadır. Toprak sıcaklı̆ı̆ının maksimum olduğu $\left(40^{\circ} \mathrm{C}\right)$ noktada toprak nem içeriği minimum (\%6) noktadadır. Çalışmanın 51'inci haftasında sıcaklığın maksimum ve nemin minimum olduğu noktada $\mathrm{CO}_{2}$ emisyonu maksimum değerdedir (Şekil 4). Bu ve buna benzer noktalarda $\mathrm{CO}_{2}$ çıkışının en yüksek değerde olması sadece topraktaki mikrobiyal faaliyetler ile bitki köklerinin aktivitesine bağlı olmayıp, kurak ve yarı kurak bölgelerde uzun dönem ve uzun güneşleme koşulları altında ayrışma ve parçalanma gerçekleştiğinden dolayı çıkan $\mathrm{CO}_{2}$ 'nn bir kısmı da bu olaydan kaynaklanabilmektedir. Yine topraktaki kireç içeriği de $\mathrm{CO}_{2}$ oluşumunu kimyasal olarak etkileyen en önemli faktörlerden biridir. Çünkü araştırma topraklarında \% 25.11-29.09 düzeyinde belirlenen kireç varlığ 1 , bu topraklarda kimyasal olarak oluşabilecek $\mathrm{CO}_{2}{ }^{\prime}$ in temel sebeplerinden biri olduğu düşünülmektedir.

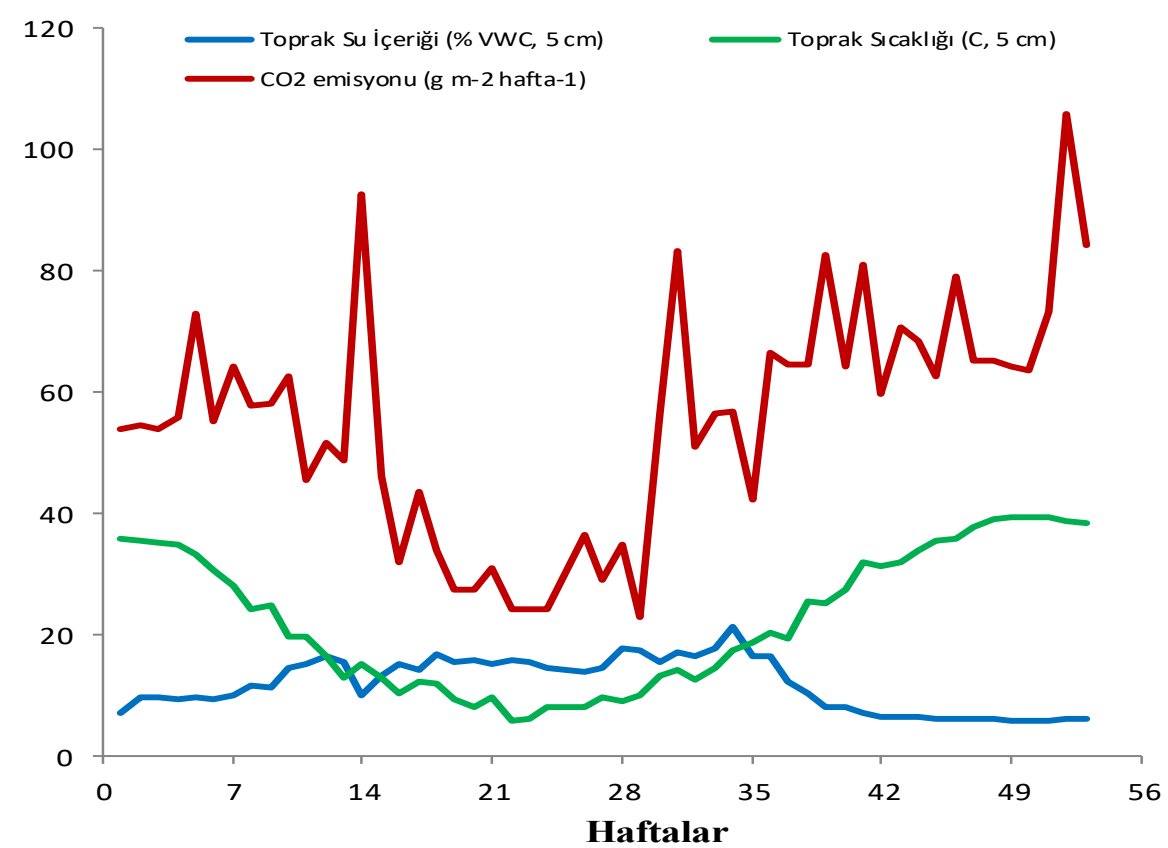

Figure 4. The relationship between weekly CO2, temperature and soil water content Şekil 4. Haftalık $\mathrm{CO}_{2}$, sıcaklık ve toprak su içeriği arasındaki iliş̧ki

Topraktan çıkan $\mathrm{CO}_{2}$-C ile iklim parametreleri arasındaki korelasyon katsayıları Tablo 3'te verilmiştir. $\mathrm{Bu}$ parametreler arasındaki korelasyon $\mathrm{P}<0.05$ önem seviyesinde incelenmiştir. Buna göre haftalık çıkan ortalama $\mathrm{CO}_{2}$-C miktarı, 5 ve $10 \mathrm{~cm}$ derinliğindeki toprak su içeriği $\left(\mathrm{R}^{2}=-0.626\right.$ ve -0.498$)$ ve PVC kabın içindeki $5 \mathrm{~cm}$ derinliğindeki toprak su içeriği $\left(\mathrm{R}^{2}=-0.620\right)$ ile önemli seviyelerde negatif, $5 \mathrm{ve} 10 \mathrm{~cm}$ toprak derinliğindeki toprak sıcaklığı $\left(R^{2}=0.695\right.$ ve 0.688$)$ ve $5 \mathrm{~cm}$ derinliğinde $P V C$ kabın içindeki toprak sıcaklığı $\left(\mathrm{R}^{2}=0.679\right)$ ile pozitif bir korelasyon bulunmuştur. Genel olarak, $\mathrm{CO}_{2}$ emisyonu ve toprak sıcaklıkları arasında yüksek oranlarda önemli ve pozitif bir korelasyon saptanmıştır. Farklı derinliklerdeki ölçülen toprak nemi ile $\mathrm{CO}_{2}$ emisyonu arasında da yüksek oranlarda önemli ve negatif bir korelasyon belirlenmiştir.

Topraktan $\mathrm{CO}_{2}$ çıkışı atmosfer, biyosfer, jeosfer ve hidrosfer arasında karbon değişimi üzerinde önemli bir rol oynamaktadır (Herbst ve Hellebrand, 2008). $\mathrm{CO}_{2}$ emisyonu ekosistemlerdeki karbon dengesi, besin döngüsü, iklim değişimi ve karbon depolaması üzerine büyük bir öneme sahiptir (Luo ve Zhou, 2006). Topraklarda $\mathrm{CO}_{2}$ emisyonu, mikrobiyal aktiviteler, bitki köklerinin faaliyetleri, topraktaki organik karbonun oksidasyonu, uzun kuraklık dönemi ve güneş ışınlarının etkisinde bulunan topraklarda karbon parçalanması sonucu oluşmaktadır.

Zaman ve mekâna bağlı olarak değişen toprak solunumunu etkileyen en önemli parametreler toprak sıcaklığı ve toprak nemidir. Toprak sıcaklığı ve toprak nemi toprak solunumunun \%80-90'ını oluşturmaktadır. Bu nedenle karbon emisyonu çalışmalarında bu iki parametreye dikkat edilmesi önemlidir. Toprak nemi, toprak sıcaklığı, bitki kökleri ve organizmalar topraktaki $\mathrm{CO}_{2}$ emisyonunu etkilerken aynı zamanda atmosferik $\mathrm{CO}_{2}$ oranını da etkilemektedir. Pek çok çalışmada (Bauer ve ark., 2012); (Zimmermann ve ark., 2010); (Dilekoglu ve Sakin., 2017a) bu konulara değinilmiştir. Bunların dışında organik madde içeriği (Liu ve ark., 2009); (Sakin, 2016), kök mikrobiyal aktivitesi (Almaraz ve ark., 2009), farklı ana materyaller (Lou ve ark., 2004) gibi faktörlerin de 

etkilediği belirtilmiştir. $\mathrm{Bu}$ çalışma sonuçlarına göre, toprak sıcaklığı $\mathrm{CO}_{2}$ emisyonu üzerindeki etkisi toprak nemine göre daha yüksek düzeydedir. Aynı iklim koşullarında ve aynı toprak özelliklerine sahip farklı işleme koşulları altında Gülle Sakin ve ark. (2015)'ın otomatik $\mathrm{CO}_{2}$ emisyon cihazı ile (LI-8100A, LI-COR) yapmış oldukları çalışmalarında da $\mathrm{CO}_{2}$ çıkışına sıcaklığın etkisinin toprak neminden daha fazla olduğunu saptamışlardır. Toprak sıcaklığ $5{ }^{\circ} \mathrm{C}$ 'nin altına düşmesi durumunda karbon emisyonunun minimum olduğu belirtilmiştir. Bu çalışmada $\mathrm{CO}_{2}$ emisyonu için kritik toprak sıcaklığı $6^{\circ} \mathrm{C}$ olarak saptanmıştır (Tablo 3).

Tablo 3. Bazı iklim parametreleri ile $\mathrm{CO}_{2}$-C arasındaki korelasyonlar

Table 3. Correlations between some climate parameters and $\mathrm{CO}_{2}-\mathrm{C}$

\begin{tabular}{|c|c|c|c|c|c|c|}
\hline Parametreler & $\begin{array}{c}\text { Ort. C } \\
\left(\text { g m }^{-2}\right. \\
\left.\text { haftalık }^{-1}\right)\end{array}$ & $\begin{array}{c}\text { Toprak } \\
\text { su } \\
(\% V W C ; \\
5 \mathrm{~cm})\end{array}$ & $\begin{array}{c}\text { Toprak } \\
\text { sicaklığı } \\
\left({ }^{\circ} \mathrm{C} ; 5 \mathrm{~cm}\right)\end{array}$ & $\begin{array}{c}\text { Toprak su } \\
\text { içeriği } \\
\text { (\%VWC; } 10 \\
\text { cm) }\end{array}$ & $\begin{array}{c}\text { Toprak } \\
\text { sıcaklığı } \\
\left({ }^{\circ} \mathrm{C} ; 10 \mathrm{~cm}\right)\end{array}$ & $\begin{array}{c}\text { PVC kabın } \\
\text { su içeriği } \\
(\% \text { VWC; } \\
5 \mathrm{~cm})\end{array}$ \\
\hline $\begin{array}{l}\text { Toprak su içeriği (\% } \\
\text { VWC; } 5 \mathrm{~cm})\end{array}$ & $-0.626^{*}$ & & & & & \\
\hline $\begin{array}{l}\text { Toprak sicaklığ }\left({ }^{\circ} \mathrm{C} \text {; }\right. \\
5 \mathrm{~cm})\end{array}$ & $0.695^{*}$ & $-0.879 *$ & & & & \\
\hline $\begin{array}{l}\text { Toprak su içeriği } \\
(\% \mathrm{VWC} ; 10 \mathrm{~cm})\end{array}$ & $-0.498 *$ & $0.795^{*}$ & $-0.750^{*}$ & & & \\
\hline $\begin{array}{l}\text { Toprak sicaklığ }\left({ }^{\circ} \mathrm{C} \text {; }\right. \\
10 \mathrm{~cm})\end{array}$ & $0.688^{*}$ & $-0.874 *$ & $0.999 *$ & $-0.765^{*}$ & & \\
\hline $\begin{array}{l}\text { PVC kabın su içeriği } \\
(\% V W C ; 5 \mathrm{~cm})\end{array}$ & $-0.620 *$ & $0.752^{*}$ & $-0.774 *$ & $0.799 *$ & $-0.775^{*}$ & \\
\hline $\begin{array}{l}\text { PVC kabın iç } \\
\text { sıcaklığı }\left({ }^{\circ} \mathrm{C} ; 5 \mathrm{~cm}\right)\end{array}$ & $0.679 *$ & $-0.865^{*}$ & $0.997^{*}$ & $-0.748^{*}$ & $0.996^{*}$ & $-0.773 *$ \\
\hline
\end{tabular}

Harran Ovası'nın işlenmiş killi topraklarında karbon emisyonu belirleme çalışmalarında toprak sıcaklığı ve toprak nemine bağlı olarak topraktan çıkan karbon miktarı $1.49 \mathrm{~g} \mathrm{C} \mathrm{m}^{-2}$ gün$^{-1}\left(5.46 \mathrm{~g} \mathrm{CO}_{2} \mathrm{~m}^{-2}\right.$ gün$^{-1}$ veya $38.22 \mathrm{~g}$ $\mathrm{CO}_{2} \mathrm{~m}^{-2}$ hafta $^{-1}$ ) olarak saptanmıştır (Sakin ve Sakin, 2015). İşlenmemiş alanlarda yapılan bu çalışmada ise, toprak nemi ve sıcaklığına bağlı olarak ortalama karbon emisyon miktarı $2.17 \mathrm{~g} \mathrm{C} \mathrm{m}^{-2}$ gün$^{-1}\left(15.152 \mathrm{~g} \mathrm{CO}_{2} \mathrm{~m}^{-2}\right.$ gün$^{-1}$ veya $55.56 \mathrm{~g} \mathrm{CO}_{2} \mathrm{~m}^{-2}$ hafta $^{-1}$ ) olarak belirlenmiştir. Bu çalışmada topraktan çıkan $\mathrm{CO}_{2}$ miktarı işlenmiş alanlardan çıkan $\mathrm{CO}_{2}$ 'in yaklaşık olarak 1.46 katı kadardır. İşlenmemiş alanların karbon emisyon oranlarının yüksek olmasının diğer bir nedeni de bu toprakların karbon içeriğinin yüksek olmasından kaynaklanmaktadır. Çalışma alanı topraklarının karbon içeriği \%2.01 (0-5 cm) ile \%1.96 (5-10 cm) olarak belirlenmiştir. Bölgede yapılmış olan bu çalışmanın sonuçları ile mevcut çalışma sonuçları arasında benzerlik ortaya çıkmıştır (Sakin ve Yanardağ, 2019).

Dünyada yapılan pek çok çalışmada sıcaklığın düşük nemin yüksek olduğu kış dönemlerinde topraktan $\mathrm{CO}_{2}$ emisyonu oranı minimumdur. Toprak solunumu toprak sıcaklığının artmasıyla artmaktadır. Toprakların toprak solunumu vejetasyon tipine, yönetim pratiklerine, çevre koşullarına ve arazi kullanım tiplerine bağlı olarak değişmektedir (Frank ve ark., 2006; Maier ve ark., 2010; Giardina ve ark., 2014; Angert ve ark., 2015; Çelik, 2018; Sakin ve Yanardag, 2019). Ancak araştırmacılar çalışmalarında toprak nemi ile toprak sıcaklığının pik noktalarını belirtmemişlerdir. Uzun kuraklık döneminden sonra aşırı yağışların düşmesi toprak canlıların yaşamını etkilerken toprakta $\mathrm{CO}_{2}$ emisyonuna neden olmaktadır (Xu ve Luo, 2012). Ancak uzun süren kuraklık döneminde toprak organizmalarının aktivitesi hakkında net bilgi olmadığı belirtilmiştir (Wu ve Lee, 2011). Toprak sıcaklığı ve nemi ile toprakta $\mathrm{CO}_{2}$ solunumu oranı arasında güçlü ilişkiler saptanmıştır (Rey ve ark., 2011; Sugihara ve ark., 2012; Forrester ve ark., 2012; Dilekoglu ve Sakin, 2017b).

Toprak $\mathrm{CO}_{2}$ emisyonu yıl içinde tüm alanlarda (işlenmiş, işlenmemiş, orman vs.) değişiklik göstermektedir. Bu değişim toprak nemi ve toprak sıcaklığı ile ilgilidir. Almagro ve ark. (2009)' in yapmış oldukları çalışmada toprak solunumu, toprak sıcaklığının artması ile Nisan ayına kadar sürekli arttığı ve bu dönemde pik $\left(12.7 \mathrm{~g} \mathrm{CO}_{2}\right.$ $\mathrm{m}^{-2}$ gün$^{-1}$ ) yaptığı belirtilmektedir. Toprak nemi \%10’un altına düştüğü ilkbaharın sonları ile kurak yaz aylarında topraktan çıkan $\mathrm{CO}_{2}$ miktarı azalmaktadır. Toprak nemi \%7.68 ve \%13.3 olduğu yaz aylarında toprak $\mathrm{CO}_{2}$ emisyonu sırasıyla $4.68 \mathrm{~g} \mathrm{CO}_{2} \mathrm{~m}^{-2}$ gün-1 ile $12.62 \mathrm{~g} \mathrm{CO}_{2} \mathrm{~m}^{-2}$ gün-1 olduğu saptanmıştır. Burada toprak neminin de 
$\mathrm{CO}_{2}$ emisyonuna olan etkisi ortaya çıkmaktadır. Ancak tüm arazi kullanım alanlarında, toprak $\mathrm{CO}_{2}$ emisyonu toprak sıcaklığının minimum ve toprak su içeriğinin maksimum olduğu kış aylarında en düşük oranlardadır.

\section{Sonuç}

Her ne kadar sıcaklık önemli bir faktör olsa da toprak neminden bağımsız düşünülemez. Onun için yapılan değerlendirmelerde mutlaka bunlar arasındaki korelâsyonlar da dikkate alınmalıdır. Özellikle kurak ve yarı kurak bölgelerde yaz dönemlerinde toprak nemi düşük olmakta ve sıcaklık yüksek seviyelerde seyretmektedir. Kurak dönemler yetersiz nem sebebi ile mikrobiyal aktivite düşük olmaktadır.

Kurak ve yarı kurak iklim bölgelerinde topraklarda $\mathrm{CO}_{2}$ emisyonunun mevsimsel değişimi iklim parametrelerinden sıcaklık ve nem faktörlerine bağlıdır. $\mathrm{Bu}$ çalışmada topraktan $\mathrm{CO}_{2}$ emisyonu üzerinde toprak sıcaklığının etkisi toprak neminin etkisinden daha fazla saptanmıştır. İklim, toprak organik madde içeriği, tekstür ve bitki besin maddeleri mikrobiyal aktiviteyi etkilediği için doğrudan $\mathrm{CO}_{2}$ çıkışını etkilemektedir.

Kurak ve yarı kurak iklim bölgelerinde bulunan işlenmemiş alanlarda topraktan çıkan $\mathrm{CO}_{2}$ işlenmiş alanlarda çıkan $\mathrm{CO}_{2}$ 'ten daha fazla olup, yaklaşık olarak 1.46 katı kadardır. Bu toprakların karbon depolama potansiyelleri sınırlı olduğu için devamlı karbon depolayamamaktadır. Bu nedenle mevcut karbon mikrobiyal faaliyet sonucu ayrışmakta ve sonunda $\mathrm{CO}_{2}$ açı̆̆a çıkmaktadır. 


\section{Kaynakça}

Açıkbaş, B., Bellitürk, K. (2016). Vermikompostun 5BB Üzerine Aşılı Trakya İlkeren Asma Fidanlarının Bitki Besin Elementleri İçerikleri Üzerine Etkisi. Tekirdă Ziraat Fakültesi Dergisi, 13 (4), 131-138.

Anonim (2019). Meteoroloji Genel Müdürlüğü. Şanlıurfa İli İklim Verileri, Ankara, https://www.mgm.gov.tr/veridegerlendirme/il-ve-ilceleristatistik.aspx?m=SANLIURFA, (Erişim tarihi: 23.09.2020)

Allison, LE, Moodie, C E. (1965). Carbonate. In: C.A, Black et al (ed). Metods of Soils Analysis. Part 2. Agronomy 9 (1). Am. Soc. of Argon., Inc., Madison, pp. 1379 - 1400, Wisconson U.S.A.

Almagro, M., López, J., Querejeta, J I., Martínez-Mena, M. (2009). Temperature Dependence of Soil CO 2 Efflux is Strongly Modulated by Seasonal Patterns of Moisture Availability in a Mediterranean Ecosystem. Soil Biology and Biochemistry 41 (3): $594-605$

Almaraz, JJ., Zhou, X., Mabood, F., Madramootoo, C., Rochette, P., Ma, B L., Smith, D L. (2009). Greenhouse Gas Fluxes Associated with Soybean Production under Two Tillage Systems in Southwestern Quebec. Soil and Tillage Research 104 (1): $134-139$.

Angert, A., Yakır, D., Rodeghıero, M., Preisler, Y., Davidson, E A., Weiner, T. (2015). Using $\mathrm{O}_{2}$ to Study the Relationships between Soil CO Efflux and Soil Respiration. Biogeosciences 12: 2089-2099.

Bauer, J., Weihermüller, L., Huisman, J A., Herbst, M., Graf, A., Sequarıs, J., Vereecken, H. (2012). Inverse Determination of Heterotrophic Soil Respiration Response to Temperature and Water Content under Field Conditions. Biogeochemistry 108:119-134.

Bellitürk, K. (2018). Some Evaluations about Use of Vermicompost in Agricultural Activity of Thrace Region, Turkey: A Review. Journal of Rice Research 6 (2): 1000193.

Bellitürk, K., Kuzucu, M., Çelik, A., Baran, M F. (2019). Antep Fıstığında (Pistacia Vera L.) Kuru Koşullarda Gübrelemenin Verim ve Kaliteye Etkileri. Tekirdăg Ziraat Fakültesi Dergisi, 16 (2), 251-259.

Bellitürk, K. (2019). Asit ve Düşük Organik Madde İçeren Toprakların Islahı: Trakya Bölgesi Örneği. Kireç Dünyası 5 (10): 19-22.

Black, CA. (1965). Methods of Soil Analysis, Part II, American Soci. of Agroninc. Pub. No: 9 Madison WI, USA.

Bouyoucus, G J. (1951). A Recalibration of the Hydrometer for Making Mechanical Analysis of Soils. Agron Jour 3: 434 -438.

Çelik, A., Sakin, E. (2017). Comparing Surface Carbon Concentrations and Some Parameters of the Soils on Which Medicinal and Aromatic Plants Grow. Applied Ecology and Environmental Research 15 (3): 1057-1068.

Çelik, A., İnan, M., Sakin, E., Büyük, G., Kırpık, M., Akça, E. (2017). Changes in soil properties following shifting from rainfed to irrigated agriculture: the Adiyaman case. Toprak Bilimi ve Bitki Besleme Dergisi, 5 (2), 80-86.

Çelik A., (2018). Carbon Dioxide Emission Measurement of Soils Where Some Medical and Aromatic Plants are Grown. International Scientific Research Congress (UBAK). 09-13 May 2018, Mardin, Turkey, 169-170,

Çimrin, K M., Yalçın, M., Keleş, N. (2019). Gaziantep ili Nizip ilçesi zeytin bahçeleri topraklarının bor durumunun belirlenmesi. Mustafa Kemal Üniversitesi Tarım Bilimleri Dergisi, 24 (1), 1-6.

Dignac, M F., Derrien, D., Barré, P., Barot, S., Cécillon, L., Chenu, C., Hedde, M. (2017). Increasing Soil Carbon Storage: Mechanisms, Effects of Agricultural Practices and Proxies. A Review. Agronomy for Sustainable Development 37 (2): 14-21.

Dilekoglu, M F., Sakin, E. (2017a). The effect of temperature and humidity in soil carbon dioxide emission. The J Anim Plant Science 27 (5):1596-1603

Dilekoglu, M F., Sakin, E. (2017b). Determination of carbon emissions in shallow soil of Harran plain, Turkey. Applied Ecology and Environmental Research 15 (4): 675-682.

Edwards, N T. (1982). The Use of Soda-Lime for Measuring Respiration Rates in Terrestrial Systems. Pedobiologia 23 (5): $321-330$.

Forrester, J A., Mladenoff, J D., Gower, S T., Stoffel, J L. (2012). Interactions of temperature and moisture with respiration from coarse woody debris in experimental forest canopy gaps. Forest Ecology and Management 265:124-132.

Frank, A B., Liebeg, M A., Tanaka, D L. (2006). Managment effects on soil $\mathrm{CO}_{2}$ efflux in northern semiarid grassland and cropland. Soil and Tillage Research 89:78-85.

Giardina, C P., Litton, C M., Crow, S E., Asner, G P. (2014). Warming-Related increases in soil CO 2 efflux are explained by increased belowground carbon flux. Nature Climate Change 4: 822-827.

Goncharova, O., Matyshak, G., Udovenko, M., Semenyuk, O., Epstein, H., Bobrik, A. (2020). Temporal dynamics, drivers, and components of soil respiration in urban forest ecosystems. CATENA 185: 104299.

Göçmez, S., Bellitürk, K., Görres, H. J., Turan, H.S., Üstündağ, Ö., Solmaz, Y., Adiloğlu, A., (2019). The Effects of the Use of Vermicompost in Olive Tree Farming on Microbiological and Biochemical Characteristics of the Production Material, Erwerbs-Obstbau, Springer Berlin Heidelberg, pp:1-8.

Görres, J H., Martin, C., Nouri-Aiin, M., Bellitürk, K. (2019). Physical properties of soils altered by invasive pheretimoid earthworms: does their casting layer create thermal refuges? Soil Systems 3 (3): 1-13). 
Grogan, P. (1998). $\mathrm{CO}_{2}$ Flux Measurement Using Soda Lime: Correction for Water Formed During $\mathrm{CO}_{2}$ Adsorption. Ecology 79: 1467-1468.

Gülle Sakin, E D., Saylan, L., Sakin, E., Altun, Ş B., Yeşilköy, S. (2015). Carbon Emission from Soil and Meteorological Variables: A Case Study in Sanliurfa. 4th International Soil and Water Resources Congress. 01-04 September, Maras /Turkey.

Herbst, M., Hellebrand, H J. (2008). Multiyear Heterotrophic Soil Respiration: Evaluation of Acoupled CO $\mathrm{CO}_{2}$ Transport and Carbon Turnover Model. Ecol Model 214 (2-4):271-283.

Horneck, D A., Hart, J M., Topper, K., Koepsell, B. (1989). Methods of Soil Analysis Used in the Soil Testing Laboratory at Oregon State University. 1-21, State of Oregon, University Publication USA

Jae, J., Tompsett, G A., Foster, A J., Hammond, K D., Auerbach, S M., Lobo, R F., Huber, G W. (2011). Investigation into the shape selectivity of zeolite catalysts for biomass conversion. Journal of Catalysis 279(2): 257-268.

Karaağaç, H A., Baran, M F., Mart, D., Bolat, A., Eren, Ö. (2019). Nohut üretiminde enerji kullanım etkinliği ve sera gazı (ghg) emisyonunun belirlenmesi (Adana ili örneği). Avrupa Bilim ve Teknoloji Dergisi (16): 41-50.

Keith, H., Wong, S C. (2006). Measurement of soil $\mathrm{CO}_{2}$ efflux using soda lime absorption: Both quantitative and reliable. Soil Biology \& Biochemistry 38:1121-1131.

Lal, R., Kimble, J M. (1997). Conservation tillage for carbon sequestration. Nutrient Cycling in Agroecosystems 49 (1-3): $243-253$.

Liu, W., Zhang, Z., Wan, S. (2009). Predominant role of water in regulating soil and microbial respiration and their responses to climate change in a semiarid grassland. Glob Chang Biol 15:184-195.

Lou, Y., Li, Z., Zhang, T., Liang, Y. (2004). $\mathrm{CO}_{2}$ emissions from subtropical arable soils of China. Soil Biology and Biochemistry 36(11): 1835-1842.

Luo, Y., Zhou, X. (2006). Soil Respiration and the Environment. Academic Press, San Diego, CA.

Maier, M., Schack-Kirchner, H., Hildebrand, E E., Holst, J. (2010). Pore-Space $\mathrm{CO}_{2}$ dynamics in a deep, well-aerated doil. Eur J Soil Sci 61: $877-88$.

Nelson, D W., Sommers, L E. (1982). Total Carbon, Organic Carbon and Organic Matter. Madison, Wisconsin, pp 539 - 579, USA.

Nowak, D J., Crane, D E. (2002). Carbon storage and sequestration by urban trees in the USA. Environmental pollution 116 (3): $381-389$.

Raich, J W., Schlesinger, W H. (1992). The Global Carbondioxide Flux in Soil Respiration and its Relationship to Vegetation and Climate. Tellus 44B: 81-99.

Rey, A., Pegoraro, E., Oyonatre, C., Were, A., Escribano, P., Raimundo, J. (2011). Impact of land degradation on soil respiration in a steppe (Stipa tenacissima L.) semiarid ecosystem in the SE of Spain. Soil Biology and Biochemistry 43:393-403.

Sakin, E., Sakin, E D. (2015). Harran Ovasının killi topraklarında karbon emisyonun ölçülmesi. GAP VII. Tarım Kongresi. 28 Nisan - 1 Mayıs 2015, Sanlıurfa.

Sakin, E., Yanardag, I H. (2019). Effect of application of sheep manure and its biochar on carbon emissions in salt affected calcareous soil in Sanliurfa Region SE Turkey. Fresen Environ Bull 28 (4): 2553-2560.

Sakin, E. (2016). Seasonal variations of carbon emissions in uncultivated soils. Oxidation Communication 39 (2): $1374-1384$.

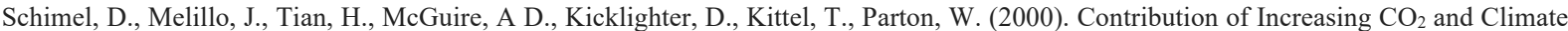
to Carbon Storage by Ecosystems in the United States. Science 287: 2004-2006.

Sugihara, S., Funakawa, S., Kilasara, M., Kosaki, T. (2012). Effects of land management on $\mathrm{CO}_{2}$ flux and soil C stock in two Tanzanian croplands with contrasting soil texture. Soil Biology \& Biochemistry 46: 1-9.

Vanhala, P., Fritze, H., Neuvonen, S. (1996). Prolonged simulated acid rain treatment in the subarctic: effect on the soil respiration rate and microbial biomass. Biology and Fertility of Soils 23 (1): 7-14

Wu, H J., Lee, X H. (2011). Short-term effects of rain on soil respiration in two new England forests. Plant and Soil 338: 329-342.

Xu, X., Luo, X. (2012). Effect of wetting intensity on soil GHG fluxes and microbial biomass under a temperate forest floor during dry season. Geoderma 170: 118-126.

Yaldız, G., Şekeroğlu, N. (2013). Küresel iklim değișikliğinde tıbbi ve aromatik bitkilerin önemi. Türk Bilimsel Derlemeler Dergisi 6(1): 8588.

Zimmermann, M., Conen, J L F., Bird, M I., Meir, P. (2012). Can composition and physical protection of soil organic matter explain soil respiration temperature sensitivity? Biogeochemistry 107:423-436. 